\title{
A História da Medicina Nuclear no INCA
}

\author{
History of Nuclear Medicine at INCA
}

\author{
Jane Benatti Antonucci' e Darcy da Silva Guimarães ${ }^{2}$
}

${ }^{1}$ Chefe da Seção de M edicina N uclear do IN CA.

${ }^{2}$ Assessor do Gabinete da Direção Geral do INCA.

Com a inauguração do novo prédio do Instituto N acional de Câncer - IN CA, na Praça Cruz Vermelha № 23, em 1957, vários setores do Instituto passaram a realizar suas atividades em dependências mais amplas e funcionais.

N essa ocasião, o Setor de Radioisótopos, parte que era do Serviço de Radioterapia, passou a contar com um cintilógrafo retilíneo Picher, que fazia cintilografia em cores, e um cintilógrafo da 0 hio, com dois detectores, para exame do corpo inteiro, e duas sondas de captação para estudos renais e tireoideanos.

Em 1963, o médico Antonio Pinto Vieira foi designado por Francisco Fialho, então Diretor do IN CA, para chefiar a nova Seção de M edicina Nuclear. Com o seu trabalho, Pinto Vieira conseguiu demonstrar o grande valor dos radiosótopos no diagnóstico e controle das neoplasias malignas. Ele exerceu a Chefia da Seção até 1982, data em que aposentou do Serviço Público Federal.

N esse ano, o médico D auro de Sá Villela Pedras foi designado para chefiar a Seção de M edicina N uclear do IN CA, participando da ampliação do setor com a incorporação de uma Gama-câmara da marca CGR e de recursos humanos - tanto técnicos como médicos -, ficando a equipe médica composta por Dauro Villela Pedras, Jane Benatti Antonucci, Léa M irian e Emerson Penque. Tempos depois, essa equipe foi complementada com a chegada dos médicos Celso M achado Cury, Rossana Corbo, D ário Sarmento e Adilson S. Almeida, este aposentado em 1999.

Em 1995, a médicaJ ane Benatti Antonucci passou a chefiar a Seção de M edicina N uclear do IN CA, que foi transferida do 20 para 030 andar, para acomodações maiores e mais confortáveis. D esde então, a Seção incorporou mais dois novos aparelhos cintilográficos com Sistema SPECT (uma STARCAM 3200i, da GE, adquirida em 1995, e uma ECAM, da Siemens, adquirida em 1999), aumentando o número de exames e implantando técnicas novas.

Em 2002, a gama-câmara STARCAM 3200i foi cedida ao H ospital G overnador João Alves Filho, da Secretaria de Saúde do Estado de Sergipe, substituída que foi por uma gama câmara digital M ILLEN N IU M da GE com SPECT e dois detectores, para exames gerais.

Atualmente, a Seção dispõe dos seguintes equipamentos, todos em operação: 02 gamacâmaras com SPECT que realizam todos oS exames realizados no serviço e estão sendo terminadas as obras de implantação da cardiologia nuclear com esteira ergométrica que deverá iniciar seu funcionamento em novembro de 2002.

Estamos integrados aos H ospitais H C II e HC III pelo sistema on line, para liberação de laudos, sendo mais confortável para 0 paciente e médico assistente, desta maneira 
agilizando o tratamento. Dispomos também de 03 quartos terapêuticos para internação e iodoterapia de pacientes com câncer de tireóide, com capacidade de internação de 10 pacientes por semana.

Em 2001, a Seção de M edicina Nuclear do INCA produziu 5.697 procedimentos, incluindo-se entre eles aqueles de iodoterapia radioativa, contando com uma equipe de sete médicos, cinco radiofarmacêuticos e treze técnicos, quatro auxiliares de enfermagem, sob a supervisão de um enfermeiro de nível superior, 03 administrativos, possibilitando a implantação e realização de vários procedimentos novos com técnicas sofisticadas, como a pesquisa de nódulo sentinela em diversas neoplasias malignas. Administração de Samário 153 para tratamento paliativo de dor óssea metastática. Porém, a história da Seção de M edicina
N uclear, mais do que a história de uma Seção e de equipes, é a história do próprio Instituto Nacional de $C$ âncer. E dos Diretores que 0 conduziram e o conduz: M ário Kröeff (1938/ 1941), Alberto Lima de M oraes Coutinho (1941/1954), Luiz Carlos de O liveira Júnior (1954/1956), Antônio Pinto Vieira (1956/ 1962), M oacyr Alves dos Santos Silva (1962/ 1963 e 1972/1974), Francisco Fialho (1963/ 1967 e 1969/1970), Jorge Sampaio de M arsillac M otta (1967/1969), U go de C astro Pinheiro G uimarães (1970/1972), A dayr Eiras de Araújo (1974/1978), João Carlos Cabral (1978), W olfgang George Lamprecht (1978/ 1979), H iram Silveira Lucas (1979/1980), Ary Frauzino Pereira (1980/1985), Geraldo M attos de Sá (1985/1986), Walter Roriz de Carvalho (1986/1990), M arcos Fernando de O liveira Moraes (1990/1998) e Jacob Kligerman (desde 1998). 